\title{
As the bell tolls: a foundation study on pancreatic cancer consumer's research priorities Carla Saunders ${ }^{1}$, Helen Gooden*2,3, Monica Robotin ${ }^{2,4}$ and Jan Mumford ${ }^{2}$
}

\begin{abstract}
Address: ${ }^{1}$ School of Medicine and Public Health, The University of Newcastle, Wallsend NSW, Australia, ${ }^{2}$ The Cancer Council NSW, 153 Dowling Street, Woolloomooloo, NSW Australia, ${ }^{3}$ Faculty of Nursing \& Midwifery, University of Sydney, Camperdown NSW, Australia and ${ }^{4}$ School of Public Health University of Sydney, Camperdown NSW, Australia
\end{abstract}

Email: Carla Saunders - carlas@netspace.net.au; Helen Gooden* - heleng@nswcc.org.au; Monica Robotin - monicar@nswcc.org.au; Jan Mumford - jmumford@nswcc.org.au

* Corresponding author

Published: 9 September 2009

BMC Research Notes 2009, 2:179 doi:10.1186/1756-0500-2-179
Received: 21 July 2009

Accepted: 9 September 2009

This article is available from: http://www.biomedcentral.com/I756-0500/2/179

(C) 2009 Saunders et al; licensee BioMed Central Ltd.

This is an Open Access article distributed under the terms of the Creative Commons Attribution License (http://creativecommons.org/licenses/by/2.0), which permits unrestricted use, distribution, and reproduction in any medium, provided the original work is properly cited.

\begin{abstract}
Background: This is the first investigation of its kind to explore the views of people affected by pancreatic cancer with regard to research priorities. Pancreatic cancer has an extremely poor outlook in terms of early diagnosis, effective treatment and survival. Those affected by the disease generally lack opportunities to voice their needs or concerns in an organised manner, link with others affected by the condition and take part in research.
\end{abstract}

Methods: This qualitative study adopts a self-selected telephone focussed discussion group approach. Information was obtained from distinct carer and patient groups after adequate controls such as the 'safe space' technique (repeatedly enquiring on and respecting the emotional needs) were implemented to protect participants from undue physical and psychological distress.

Results: Five themes emerged overall, with three themes being common between the patients and carers groups. Early detection, clinician communication and public awareness were areas of recurring discussion and consensus for both groups. The fourth theme to emerge for the patient group centred on quality of care, while the fourth theme of the carer group focused on the need for more and improved treatment options.

Conclusion: Research priorities for pancreatic cancer consumers have been identified via an investigation that was tailored to meet exceptional needs. This research gives us a primary understanding of the role that pancreatic cancer patients can play in identifying areas of research that are responsive to their needs and priorities when suitably planned. Importantly it also provides a much greater understanding of the grim realities of the disease for those affected. This work is likely to be of value to anyone planning to work with those with a time limited, challenging condition.

\section{Background}

Pancreatic cancer (PC) is a deadly disease. The early vague symptoms are easily overlooked and high-risk delays in diagnosis are very common. Only around $10 \%$ of patients are considered for surgical treatment [1]. PC is the fourth leading cause of death in Western societies and recently the national rate of new cases in Australia has increased by $30 \%$ [2]. The ageing of the Australian population means 
that a proportionate increase in the number of people affected by PC, including carers, can be expected. Currently, few formal protocols exist for best clinical practice in PC management and no multidisciplinary care teams are reported [3].

There has been little improvement in the 5 year PC survival rate over the last few decades which have remained extremely low at around 5\% with the majority of patients ( $90 \%)$ dying within a year of diagnosis [4]. This compares very poorly with relative 5 year survival rates for more common malignancies such as melanoma, breast and prostate cancer which are greater than $80 \%$, and for all cancers combined (65\%) [5]. Contributing to this unfortunate situation is the long-standing relative lack of scientific knowledge of the disease; including research in all aspects, from aetiology through to effective palliative care, and an understanding of how those affected endure in daily life.

Research can lead to new or advances in treatment, improved life expectancy, better quality of life, reduced social burden and a wide range of other potential benefits. Until recently, the Australian scientific community, who largely determine priorities for cancer research, had not often selected PC. Dedicated funding programs targeting this cancer and other understudied human diseases have now been developed by a key government research funding body to encourage a more balanced approach in the spread of research across different diseases with the goal of reducing occurrence, morbidity and adverse outcomes [6].

Cancer Council NSW (CCNSW) is NSW's largest publicly funded cancer charity, which supports a significant proportion of Australia's cancer research. In 2006, one of the research grant schemes of CCNSW, the Strategic Research Partnership Grant [7], founded a network of key PC researchers and consumers affected by PC. An important function of the NSW Pancreatic Cancer Network [8] has been to systematically define critical research issues and opportunities that could accelerate progress in PC research in Australia. The rigorous prioritisation process began with a literature review, followed by structured interviews with key opinion leaders in the field, whose recommendations were then fed into a Delphi consensus process. The recommendations from the Delphi and discrete consumer involvement processes were ultimately prioritised via a nominal group procedure.

The aim of this paper is to describe the technique used to capture consumer priorities in PC research, together with the findings of the investigation. Consumers are recognised as patients and carers of people diagnosed with PC.
Cancer research is a matter of great public interest in NSW [9] and it is very important to CCNSW that both researchers and consumers are involved in research decision making processes [10], as failure to involve the community is likely to result in important areas of inquiry not being recognised. Involving consumers in research prioritisation is still a novel process both in Australia and in other countries, and seeking consumer views on research priorities in PC presents additional challenges, as diagnosis at an advanced stage, rapid disease progression and overt symptoms, including pain, limits the applicability of traditional methods of consumer consultation.

Currently the academic literature tells us that consumers have had dialogue with research funders about research priorities/gaps, they have been involved in the priority ranking of pre-established research questions and as members on committees they have collaborated with scientists to prioritise research across a range of health topics including breast cancer, mental health, physical and complex disabilities, young people, cystic fibrosis and HIV [11-13]. Although less common, consumers have also independently identified issues and set research agendas for specific cancer types [14], nevertheless we have been unable to identify any inquiries that provide those affected by pancreatic cancer the opportunity to interact, discuss and identify research priorities that are important to them.

\section{Methods}

This study was designed in consultation with a key stakeholder group comprising pancreatic cancer researchers, consumers and representatives of CCNSW. The Concord Hospital Human Research Ethics Committee (NSW, Australia) approved the research. Informed consent was gained from all research participants.

Self-selected participants were recruited from CCNSW website and newsletter information which described the opportunities and benefits of involvement in a newly launched CCNSW Pancreatic Cancer Support Project which was established to identify and address unmet supportive care needs of PC patients, and current or bereaved carers. Consumers opting into the Project were informed of the opportunity and invited to take part in a focused discussion to identify pancreatic cancer research priorities. Voluntary and informed consent to participate in the research was gained after all relevant information was provided and interested persons assured us they had adequate understanding of the study requirements.

Participants were given the option of a traditional face-toface discussion or one conducted by telephone, with telephone delivered focussed discussion the preferred option. 
One discussion group comprised patients with a PC diagnosis while another involved current and bereaved carers of PC patients. Separating the groups allowed for focussed discussion on issues that particularly affected each group.

Other investigators have used teleconference focussed discussions as the major/sole way to collect data, primarily to overcome distance and participant particular needs, and found them to be successful [15-17]. The limitations highlighted in these studies such as the increased difficulty in controlling participants using the phone method were taken into account in the design of the current study.

The focussed discussion method was selected so we could examine not only what PC consumers thought, but also why they thought it via comparing and contrasting personal experiences and perspectives in group discussion. The basic assumption of this interpretive approach was that relevant information would be gained through interaction with others, shared meanings and conclusions.

As the research involved gaining an in-depth understanding of issues, including an exploration of the reasons and context for participants' viewpoints and actions, the facilitators agreed on a 'safe space' approach prior to the focus groups. This approach of repeatedly enquiring on and respecting the emotional needs of participants allowed them to openly disclose (and acknowledge in others) emotional and/or physical distress without fear of disrupting the discussion, particularly when the dialogue centred on suffering and/or death $[18,19]$.

The facilitated discussions were audiotaped and subsequently transcribed. Two CCNSW telephone support group counsellors, one acting as moderator; an independent qualitative researcher, and the Project coordinator, as subject expert, facilitated the group discussions. All participants were provided with the purpose and ground rules, and were assured of the confidential nature of the information gathered during the discussions. The moderator also explained the need for audio-recording the discussion for analysis purposes.

At the commencement of the focussed discussions participants in each group were asked the question: Where would you like to see progress in pancreatic cancer being made? After participants raised and discussed each issue they felt was important to the topic, the facilitator fed the main points back to confirm the interpretation of comments and to reach agreement on the main themes of the discussion.

Before ending each group discussion by formally thanking participants, the moderator provided participants with information on the cost free CCNSW professional tele- phone support services to provide them with an ongoing avenue to speak about their experiences and concerns in the future.

\section{Data analysis}

A thematic content analysis was manually conducted with pattern recognition within the data identified after careful listening to the audiotape and reading/re-reading the transcripts by two researchers (CS and MR) independently. Acknowledging the context and participants of the research, repeating issues were identified and clustered, and subsequently developed into focal themes.

\section{Results}

\section{Demographics}

Twelve people responded to the invitation to participate in the study with eleven taking part after ill health prevented the participation of one male. Five current and bereaved carers made up one group, with one bereaved carer providing email responses to the questions raised with the group. Six people diagnosed with PC took part in the other phone group discussion. Table 1 provides the demographic characteristics of the research participants.

\section{Identified themes}

The carers and patients discussion groups each lasted approximately one hour. For the most part, discussion was based on personal experiences rather than opinion or conjecture. The audiotapes provided an understanding of the tone of conversations and the levels of urgency particular topics produced. Overall, participants in each group verbally expressed a range of emotions throughout the session from anger and frustration to grief. Most were active information providers and many expressed considerable worry. In general, there was no area of discussion in which each group of participants failed to reach general consensus.

Table I: Demographic Characteristics of the Research Participants

\begin{tabular}{lcc}
\hline & \multicolumn{2}{c}{ Focus Groups $(\mathbf{n}=\mathbf{I} \mathbf{I})$} \\
\hline $\begin{array}{l}\text { Gender } \\
\text { Male }\end{array}$ & I (patients) & 2 (carers) \\
$\quad$ Female & $\mathrm{I}$ & $\mathrm{I}$ \\
$\begin{array}{l}\text { Age ranges (years) } \\
\text { Male }\end{array}$ & 5 & 4 \\
$\quad$ Female & $70-79$ & $60-69$ \\
$\begin{array}{l}\text { Place of Residence } \\
\text { Urban } \\
\text { Regional/rural }\end{array}$ & $30-59$ & $30-49$ \\
\hline Unknown & 4 & 4 \\
\hline
\end{tabular}


Five themes emerged overall, with three being common between the patients and carers groups. Early detection, clinician communication and public awareness were areas of recurring discussion and consensus for both groups. The fourth theme to emerge for the patient group centred on quality of care, while the fourth theme of the carer group focused on the need for more and improved treatment options.

Tables 2 and 3 provide a complete overview of the identified focal themes and the repeated issues from which they were derived for each group.

\section{Early Detection}

All participants appeared to have a well-developed understanding of the lack of current knowledge with regard to the causes of pancreatic cancer and the important benefits of early cancer detection. Many expressed concern for the urgent need for improvements in the early detection and formal diagnosis of pancreatic cancer not only for themselves or their loved ones, but for others who may develop the disease in the future:

"I would like to see some work done in the area of symptoms and diagnostic tools so people who have got a problem can hopefully get a quicker result"

Some pointed out their low personal health locus of control with regard to detecting pancreatic cancer:

"I found out when it was too late because I had no symptoms to indicate a tumour of the pancreas "

Others offered ways that research might find solutions to the problem of asymptomatic early detection:

"I was given to understand that all cancers... are a genetic failure of some sort. A mistake is multiplied on and on and gets out of control. It's like the body has a spell-check system, putting it very simply. A word can be spelt wrong but it's still a word and it's not identified. Is there any way of looking at the body's spell-check system to see if there are any mistakes there that haven't been detected?"

\section{Clinician Communication}

All participants verbally expressed some alarm, many with an underlying tone of disbelief, in the insensitive nature of dialogue used by the clinicians in the provision of the pancreatic cancer diagnosis and/or management options.

"I hate him for what he said .....5 o'clock on a Friday night I'm a healthy person, I'm lively, I had a life planned to 95, and he (doctor) told me I would be dead in six to 18 months. I was stunned......"
Some felt it was extremely important to be allowed to express their own perceptions of their illness; however their clinicians had not provided this opportunity:

"Anything we mentioned was virtually cast aside, almost contemptuously... The prognosis may be dismal, but my wife was entitled to a lot more than that. The human spirit demands more than that"

One carer came to the defence of medical specialists and offered a solution to the problem:

"That conversation regarding pancreatic cancer is never going to be a nice one and we have to avoid shooting the messenger there. Maybe there could be some protocol that specialists follow a little more thoroughly"

There was general agreement in both the carer and patient groups for the pressing need for health professional communication guidelines which take into account the sensitivity of the individual affected by pancreatic cancer.

\section{Public Awareness}

Overall there was low confidence in the ability of available public information to provide all that was needed by people affected by PC.

" see a priority in education/awareness of pancreatic cancer because I've spoken to people who don't even know what it is or where it is"

Particular concerns with regard to public awareness of pancreatic cancer differed somewhat between the patient and carer groups. Patients highlighted the need for reliable information on effective treatments:

"Some people might even decide to go overseas for treatment and to try different things. So information is very important. There are many other alternatives and some of them may not be cheap"

One patient believed their illness was not taken as serious as it should have been by others in the community because of a lack of general awareness. Other patients felt that the available information on PC needed to be made more easily accessible than it currently was:

"We need a central information point, whether its written literature or whatever, that can be referred to immediately"

There was general consensus among carers for the need for public information that had the potential to save lives in the future: 
Table 2: Pancreatic cancer patients repeated issues and focal themes

\begin{tabular}{|c|c|}
\hline Recurring issue & Focal theme \\
\hline $\begin{array}{l}\text { "I would like to see some work done in the area of symptoms and diagnostic tools so people who have got a problem can hopefully } \\
\text { get a quicker result" } \\
\text { "People that have had gallstones and have had their gall bladder out, and I } 8 \text { months later it's been diagnosed as pancreatic cancer. } \\
\text { So it's those sorts of correlations and the diagnostic tools need to be fine-tuned" } \\
\text { "I agree with you ... I had to have a battery of tests to sort mine out, basically because I was pretty sick at the time. I would like to } \\
\text { see the testing simplified a bit. I was sick for a couple of months before, but I had to be sick enough to be in hospital before it was } \\
\text { found" } \\
\text { "Cancer is the silent killer. By the time I was diagnosed it was too late. "Mine had already moved over to the liver and the spleen and } \\
\text { so there was no surgery involved because there were too many organs" } \\
\text { "Early diagnosis would be ideal. I found out when it was too late.... } \\
\text { "People need to get to the doctor before it's too late so they can have options" }\end{array}$ & Early detection \\
\hline $\begin{array}{l}\text { "I first heard of my pancreatic cancer on I } 8 \text { July when I first went in to see the doctor. He sent me straight for an MRI. I hate him } \\
\text { for what he said when I came back five hours later: } 5 \text { o'clock on a Friday night I'm a healthy person, I'm lively, I had a life planned } \\
\text { to 95, and he told me I would be dead in six to I } 8 \text { months. I was stunned...... I think what I would like to say here is we must have } \\
\text { information presented in a professional form" } \\
\text { "While treatment is happening and I get side effects, the nurses never clarify that it is a side effect. They just send me to my GP and } \\
\text { unfortunately my GP is very much like your GP - I don't get a lot of information. He needs correct information about side effects of } \\
\text { different types of treatment and there was nothing" } \\
\text { "Regarding my diagnosis, I believe strongly that the doctor should have been able to refer me, or the next lot of people that it } \\
\text { happens to, to a counsellor or to someone who will actually give you a cup of tea for a start. The diagnosis should not be delivered } \\
\text { to people like it was to me. "If you were sick for a period of time, you could expect something like that, but it was like delivering a } \\
\text { life sentence when you hadn't murdered anyone and weren't on trial" } \\
\text { "I (also) believe that anybody who has been diagnosed with cancer should have their next appointment, as soon as possible, with a } \\
\text { counsellor" } \\
\text { "As well as the diagnosis, I was just hit with - you know when you find pancreatic cancer it's usually too late and there's not much } \\
\text { that can be done about it. That seemed to be the general attitude. I was in hospital at the time and it just seemed to be the attitude } \\
\text { amongst all medical professions, right down from the intern to the specialists" } \\
\text { "Some people want to take part in trials as they want the latest in treatment. Could that be part of an information package with } \\
\text { regard to options?" } \\
\text { "I came away and, even in the horror of things, I said to my friend that he sounds like a very good used car salesman. So he offered } \\
\text { me one (chemo option) with another three. I asked him what if and he quickly gave me a very short spiel of the risks attached" }\end{array}$ & Clinical communication \\
\hline $\begin{array}{l}\text { "When someone says they have this cure and I say "yes, but it's only for breast or bowel cancer", which is nothing compared to what } \\
\text { I have.... "We need the information out there that it is advanced, unique and aggressive.... I agree with general community } \\
\text { awareness because people need to know. I didn't know that the pancreas was so important...." } \\
\text { "We need a central information point, whether its written literature or whatever, that can be referred to immediately" } \\
\text { "Some people might even decide to go overseas for treatment and to try different things. So information is very important. There are } \\
\text { many other alternatives and some of them may not be cheap" } \\
\text { "Maybe if people knew what some of the symptoms were, like ovarian cancer, they would go and get checked" } \\
\text { "The other suggestion is the immediate sharing of information. You hear something and you would like to assist and support that } \\
\text { person...... I would be only too happy to volunteer my time for so many hours a week to help with that if I could" }\end{array}$ & Public awareness \\
\hline
\end{tabular}

"A few of us have had the Whipple procedure, but there are variations within the procedure itself. I know that most progress has been made in America and I'm sure there are various good reasons why there are delays in getting that information here. I wonder whether we can speed up that process or have our surgeons trained more quickly"

"It sounds awful but it sometimes does seem to be the quality of your GP that gets the results quicker too and some of the medical profession not even knowing, so there's a lack of awareness as well"

"I went to the doctor last week and I couldn't get in to see my regular doctor so I just saw one at the local medical centre. I told him I had had a Whipple procedure. He had never heard of a Whipple procedure and this is a doctor"

"There seems to be a lack of awareness with GPs and also specialists even just knowing about enzymes. Some people say their doctor has never mentioned it, and l've spoken to a few people who have had a Whipple procedure"

"My naturopath mentioned enzymes so I'm taking a supplement. That's what I was saying before - it's either lack of information or people just say to keep eating normally, which is not the right thing to do because everyone is different and people react differently to different foods"

"At no time was I given an option. I have heard from other people that there are different types of medication that may be more costly; however, they were never given the choice to decide to pay for the cost of more expensive medication....... I think it's up to the cancer patient to make a decision as to which treatment is more suitable for them and whether they have the means to pay for more expensive drugs not covered by Medicare or a private fund"

"I believe that we need a coordinated group of people who are, say, oncologists and surgeons and radical people and alternatives" 
Table 3: Carers repeated issues and focal themes

\begin{tabular}{|c|c|}
\hline Recurring issue & Focal theme \\
\hline $\begin{array}{l}\text { "With the diagnosis, I wish there was some sort of way they could have done it more quickly" } \\
\text { "From my wife's experience, it was I } 2 \text { months or even longer.... We were backwards and forwards to doctors. It was only in the } \\
\text { latter stages that it was diagnosed" } \\
\text { "From my experience as well, that it was the detection ... and the diagnosis which was delayed which meant the disease had } \\
\text { progressed" } \\
\text { "I can only echo what the others have said. The issue, certainly in my mother's case, was no detection... it was only when the cancer } \\
\text { had spread" } \\
\text { "It just seems that early detection is the really only useful thing that can help in saving lives" } \\
\text { "I totally agree with everything that everyone has said today. Early detection.... if that can all be brought in to help other people" }\end{array}$ & Early detection \\
\hline $\begin{array}{l}\text { "When the actual first diagnosis was given to us, we had an unfortunate experience as it was rather brutal. My wife was told to get } \\
\text { her affairs in order. That's not treating the individual as a whole person. We just felt very badly let down" } \\
\text { "I didn't feel that the manner of delivery was particularly warm. It's almost like some of the specialists are so experienced with what } \\
\text { they're doing that they lose sight of the fact that for the person who's been diagnosed, it's the first time they've ever heard these } \\
\text { words. Very often what's been told is there is actually nothing that can be done. Maybe there could be a set of words and } \\
\text { communication could be improved a little bit?" } \\
\text { "Anything we mentioned was virtually cast aside, almost contemptuously... The prognosis may be dismal, but my wife was entitled to } \\
\text { a lot more than that. The human spirit demands more than that" } \\
\text { "I think guidelines would be helpful there, taking into account the sensitivity of the individual" } \\
\text { "(The) ways that the doctors come out and tell you. There have to be some guidelines that they need to go by in a situation like this" } \\
\text { "I think you reach a point where you can't read anymore and you can't search the internet anymore and you just need somebody to } \\
\text { sit next to you and talk to you and explain things to you" } \\
\text { "That conversation regarding pancreatic cancer is never going to be a nice one and we have to avoid shooting the messenger there. } \\
\text { Maybe there could be some protocol that specialists follow a little more thoroughly. No-one is ever going to want to hear it so it's } \\
\text { never going to be well received" }\end{array}$ & Clinical communication \\
\hline $\begin{array}{l}\text { "I see a priority in education/awareness of pancreatic cancer because I've spoken to people who don't even know what it is or where } \\
\text { it is" } \\
\text { "People have got to know what pancreatic cancer is and what some of the symptoms are, and I think we all acknowledge they are } \\
\text { very vague, but the sharpening of that focus on "this could be" or "you need to". It's only when we know about something that we'll } \\
\text { follow up on it" } \\
\text { "Pancreatic cancer may have been very familiar for an oncologist, but for the individual it isn't" } \\
\text { "When my mum's diagnosis came out, I was very much in the dark. I didn't get any information" }\end{array}$ & Public awareness \\
\hline $\begin{array}{l}\text { "When my father was diagnosed, we had some trouble making a decision about whether to just go with chemotherapy or the } \\
\text { surgical option. We were having difficulty trying to ascertain which the best way to go was and we couldn't find a lot of information } \\
\text { on what had a better outcome or did surgery exacerbate things? So this was another issue that came up with our family... treatment } \\
\text { options" } \\
\text { "Less painful and distressing treatment" } \\
\text { "I know everything is hypothetical, but you have your operation and go through all of that, but there are really not enough options for } \\
\text { you to make decisions about what you will or won't do" }\end{array}$ & Treatment options \\
\hline
\end{tabular}

"People have got to know what pancreatic cancer is and what some of the symptoms are, and I think we all acknowledge they are very vague, but the sharpening of that focus on "this could be" or "you need to". It's only when we know about something that we'll follow up on it"

\section{Quality of Care}

The patient group was united in their thinking on the need for improvements in the standard and consistency of clinical care and understanding of PC:

"A few of us have had the Whipple procedure, but there are variations within the procedure itself. I know that most progress has been made in America and I'm sure there are various good reasons why there are delays in getting that information here. I wonder whether we can speed up that process or have our surgeons trained more quickly"
Health professional team coordination was also identified as being important:

"I believe that we need a coordinated group of people who are, say, oncologists and surgeons and radical people and alternatives"

\section{Treatment Options}

Carers voiced the need for improved and additional treatment options for PC:

"I know everything is hypothetical, but you have your operation and go through all of that, but there are really not enough options for you to make decisions about what you will or won't do" 


\section{Study Strengths and Limitations}

To guarantee an accurate summary of the group discussion and give an assurance that meaning had been correctly captured, all topics raised were summarised during the discussions to give participants an opportunity to immediately confirm or alter. This approach adds strength to the study's internal reliability and validity.

While the qualitative methodology used in this study is likely to be the most appropriate to gather information from this highly vulnerable group where there are only small numbers available to participate in research at any one time, it has several limitations. The primary study limitation is related to the small number of participants and the convenience nature of the sampling strategy which significantly limits the ability to broadly generalise the findings. Furthermore, the small sample size could mean that the full breadth of concerns of PC consumers may not have been adequately captured. There is a critical need for additional research to further validate both our findings and the utility of a telephone-based approach to focussed discussions.

\section{Discussion}

The ethical and practical issues of inquiries with people with advanced cancer need to be carefully planned and appropriate safeguards implemented. Facilitated telephone discussion groups supported by trained counsellors allowed us to reliably and suitably canvass the views of a highly vulnerable consumer group. The approach provided PC patients and carers the opportunity to become involved in the research priority-setting process in a manner that created minimal disruption to their lives, and took into account varying levels of pain, mobility and psychological distress. It was a welcomed opportunity for these groups to express their needs in terms of research.

One of the difficulties of engaging PC consumers in research is the relatively short time between disease diagnosis and death. Time-economy was a fundamental consideration in the planning and implementation of the current research. PC develops and spreads silently, and closes in swiftly. Engaging with people who suffer from this highly lethal, time limited disease is challenging as there is often only a small window of opportunity available. Capturing those affected early via established mechanisms such as targeted projects, patient advice lines or clinician referrals are likely to be the best avenues to provide those interested with the opportunity for research involvement.

Research areas perceived by consumers to aid progress in PC research in Australia have been identified via discreet focussed discussions. Based on the direct experiences of PC consumers, five themes have been identified as being important subjects for further research. Early detection, clinician communication, public awareness, quality of care and improved treatment options are concluded to be priorities for improving wellbeing and survival in PC. The lack of existing similar investigations indicates the difficulty of the task of sampling and investigating the priorities held by PC consumers.

A common criticism of consumer involvement in expert domains is the potential to obtain individual extreme perspectives. While we found clear areas of accordance and difference between the priorities of PC consumers and researchers, the identified consumer priorities are not beyond the realms of reality or action; this supports the growing argument for more involvement of consumers in health and medical research generally.

We found general agreement between the research priorities of consumers and those of researchers who took part in our consensus process in the areas of early detection, quality of care and the need to identify optimal treatments. Priority areas that differed between the two groups included the identification of prognostic markers; the most common disease and treatment related sequelae of PC on patients and their carers and strategies for managing them; patient-doctor communication and consumer information on pancreatic cancer.

The importance of early diagnosis and more effective treatment for pancreatic cancer, including options for defining patients at high risk of pancreatic cancer, and developing methods for detecting pancreatic tumours at an early stage is starting to receive increasing attention from a number of researchers globally [20-22] although it lags well behind similar research on other cancer types such as breast cancer. In addition, there is a growing but relatively early focus on the biology of PC which is hoped will lead to multiple potential therapeutic options by directing treatment at these new biologic targets $[23,24]$.

Sensitive information is normally conveyed to patients and carers by clinicians through verbal communication. Just how this is done varies considerably from clinician to clinician [22]. The general need for further research into the best methods for communicating serious health problems effectively and respectfully has been recognised by some researchers, although effective solutions and noteworthy improvements remain elusive [26-28]. Guidelines for effectively communicating bad news to cancer patients have been developed and widely distributed to oncologists $[29,30]$. However, a review of the effectiveness of these guidelines has found that they may not reflect the complexities of patient-oncologist interactions [31]. Other studies have found that the ability of the cancer patient to recall what the oncologist has said is influenced 
by prognosis, with patients with a poorer prognosis recalling significantly less [32]. The findings of poor patient acceptability, didactic approach and lack of wider family communication have led to a recent inquiry to call for an urgent revision of existing terminal prognosis communication protocols and practices taught in medical school training [33].

More widespread and easily accessed public information on pancreatic cancer has been recognised by a handful of existing overseas patient support organisations $[34,35]$ as critical in raising awareness of possible symptoms, providing a reliable avenue for accurate and current treatment and management information, and linking people to answers and others affected by the disease. Unlike studies that exist for many other cancer types [36-39] we could find no formal inquiry investigating the best approaches, true level of availability and effect of relevant information resources on PC consumers.

The growing impetus to better address PC, including the results of this first consumer inquiry, may help increase focus by, and pressure on, health and medical research funding organisations to further discriminate in favour of this under prioritised and underfunded health problem.

\section{Conclusion}

This research gives us the first understanding of the role that consumers with a known limited life expectancy can play in identifying research that is responsive to community needs and priorities when suitably planned and implemented. Research has traditionally been controlled by scientists to the exclusion of a societal perspective. Investigating the issues faced by PC patients and carers goes a long way towards understanding how science might best 'fit' with their needs, contexts and expectations. The research also provides a much better understanding of the stark realities of the disease for those affected.

\section{Competing interests}

The authors declare that they have no competing interests.

\section{Authors' contributions}

CS undertook the data analysis and literature review, and was the primary author of the paper; HG coordinated the project, collected the data, contributed preliminary input to the paper; and continues to oversee the associated program; MR undertook the data analysis and contributed to the development, drafting and editing of the paper; JM providing valuable project assistance and comments and suggestions during the preparation of the paper.

\section{Acknowledgements}

The authors gratefully acknowledge the contribution of the other members of the project team. Also thanks to Professor Andrew Biankin in providing comments and suggestions during the preparation of this paper, and the
NSW Pancreatic Cancer Network and the STREP Steering Committee which provided critical oversight for the project. Our sincere thanks go to those affected by PC who volunteered their precious time and were enthusiastic participants of this study.

\section{References}

I. Thomson B, Banting S, Gibbs P: Pancreatic cancer current management. Australian Family Physician 2006, 35(No 4).

2. Australian Institute of Health and Welfare and Australasian Association of Cancer Registries Cancer in Australia: an overview, Cancer Canberra 2006 [http://www.aihw.gov.au/publications/ index.cfm/title/l0389].

3. NSW Cancer Institute: Cancer Services Directory. [http:// www.cancerinstitute.org.au/cancer inst/patients/directory.html]. Accessed Sept, 2008

4. Hariharan D, Saied A, Kocher HM: Analysis of mortality rates for pancreatic cancer across the world. HPB (Oxford) 2008, I0(I):58-62.

5. Population Health Division: The health of the people of New South Wales - Report of the Chief Health Officer [http:/l www.health.nsw.gov.au/public-health/chorep/can/can surv cat.htm]. Sydney: NSW Department of Health Accessed Sept, 2008

6. Cancer Australia: Priority driven research. [http://www.cancer australia.gov.au/research-and-clinical-trials/priority-drivearch.aspx]. Accessed Aug $8^{\text {th }} 2008$

7. Cancer Council NSW: Strategic Research Partnership Grant, Information for Applicants. [http://www.cancercouncil.com.au/ editorial.asp?pageid=2012].

8. The NSW Pancreatic Cancer Network [http://www.pancreat iccancer.net.au/]

9. Saunders Carla, Girgis Afaf, Butow Phyllis, Crossing Sally, Penman Andrew: Beyond scientific rigour: Funding cancer research of public value. Health Policy 2007:17573144.

10. Saunders Carla, Crossing Sally, Girgis Afaf, Butow Phyllis, Penman Andrew: Operationalising a model framework for consumer and community participation in health and medical research. Aust New Zealand Health Policy 2007, 4(I): I 3. I759265 I

II. Oliver Sandy, Clarke-Jones Lorna, Rees Rebecca, Buchanan Phyll, Gabbay John, Gyte Gill, Milne Ruairidh, Oakley Ann, Stein Ken: Methods of involving consumers in identifying and prioritizing research topics: a systematic review. Poster Presentation. Cochrane 200I, I:pa0I6 [http://www.biomedcentral.com/ abstracts/COCHRANE/I/pa016/].

12. Royle Jane, Oliver Sandy: Consumer involvement in the health technology assessment program. International Journal of Technology Assessment in Health Care 2004, 20:493-497.

13. Oliver S: 'The Progress of Lay Involvement in the NHS Research and Development Programme'. Journal of Evaluation in Clinical Practice 1996, 2(4):273-80.

14. Wright David, Corner Jessica, Hopkinson Jane, Foster Claire: Listening to the views of people affected by cancer about cancer research: an example of participatory research in setting the cancer research agenda. Health Expectations 2006, 9:3-I2.

15. Appleton A: Living with an Increased Risk of Breast Cancer: An Exploratory Study Using Telephone Focus Groups. Psycho-Oncology 2000, 9(4):36I.

16. Anthony Williams G, Roderic Abbott R, Kay Taylor D: Using Focus Group Methodology to Develop Breast Cancer Screening Programs that Recruit African American Women. Journal of Community Health 1997, 22(Number I).

17. Veale A: Creative methodologies in participatory research with children. In Researching Children's Experience: Approaches and Methods Edited by: Greene S, Hogan D. London: Sage Publications; 2005.

18. Ruef MB, Turnbull AP: Stakeholder Opinions on Accessible Informational Products Helpful in Building Positive, Practical Solutions to Behavioural Challenges of Individuals with Mental Retardation and/or Autism. Education and Training in Mental Retardation and Developmental Disabilities 200I, 36: I45.

19. Rebecca Campbell, Tracy Sefl, Wasco Sharon M, Ahrens Courtney E: Doing Community Research without a Community: Creating Safe Space For Rape Survivors: Process of Community Research and Action. American journal of community psychology 2004, 33(3-4):253-26I. 
20. Hassan MM, Bondy ML, Wolff RA, Abbruzzese JL, Vauthey JN, et al.: Risk factors for pancreatic cancer: case-control study. $\mathrm{Am} J$ Gastroenterol 2007, I 02( ( 2):2696-707. Epub 2007 Aug 3 I

21. Gumbs AA: Obesity, Pancreatitis, and Pancreatic Cancer. Obes Surg 2008.

22. Duell EJ, Bracci PM, Moore JH, Burk RD, Kelsey KT, Holly EA: Detecting pathway-based gene-gene and gene-environment interactions in pancreatic cancer. Cancer Epidemiol Biomarkers Prev 2008, I7(6): 1470-9.

23. The Garvan Institute for Medical Research: Pancreatic Cancer. [http://www.garvan.org.au/research/research-groups/pancreatic-can cer.html/?searchterm=assistant]. Accessed Sept 2008

24. The Cancer Council NSW: Innovator Grants in Pancreatic Cancer. [http://www.cancercouncil.com.au/editorial.asp?pageid=2433]. Accessed Aug 8th 2008

25. Greenberg Peter B, Walker Christine, Buchbinder Rachelle: Optimising communication between consumers and clinicians. MJA 2006, 185(5):246-247.

26. Ruiz-Moral R, Pérez Rodríguez E, Pérula de Torres LA, de la Torre J: Physician-patient communication: a study on the observed behaviours of specialty physicians and the ways their patients perceive them. Patient Educ Couns 2006, 64(I-3):242-8. Epub 2006 Apr 4

27. Fröjd C, Lampic C, Larsson G, Birgegård G, von Essen L: Patient attitudes, behaviours, and other factors considered by doctors when estimating cancer patients' anxiety and desire for information. Scand J Caring Sci 2007, 2 I (4):523-9.

28. Baile WF, Buckman R, Lenzi R, et al.: SPIKES: A six-step protocol for delivering bad news--Application to the patient with cancer. Oncologist 2000, 5:302-3II.

29. Rosenbaum ME, Ferguson KJ, Lobas JG: Teaching medical students and residents skills for delivering bad news: $A$ review of strategies. Acad Med 2004, 79:107-1 17.

30. Back AL, Arnold RM, Tulsky JA, et al: Teaching communication skills to medical oncology fellows. J Clin Oncol 2436, 21:2433-2003.

31. Eggly S, Penner L, Albrecht TL, Cline RJ, Foster T, Naughton M, Peterson A, Ruckdeschel JC: Discussing bad news in the outpatient oncology clinic: rethinking current communication guidelines. J Clin Oncol 2006, 24(4):716-9. Review

32. Jansen J, Butow PN, van Weert JCM, van Dulmen S, Devine RJ, Heeren T], Bensing JM, Tattersall MHN: Does Age Really Matter? Recall of Information Presented to Newly Referred Patients With Cancer. J Clin Oncol 2008, 26(33):5450-5457.

33. Wittenberg-Lyles EM, Goldsmith J, Sanchez-Reilly S, Ragan SL: Communicating a terminal prognosis in a palliative care setting: deficiencies in current communication training protocols. Soc Sci Med 2008, 66 (I I):2356-65. Epub 2008 Mar 5

34. Pancreatic Cancer Awareness Foundation [http://www.pca ware.org/]

35. The Rolfe pancreatic Cancer Foundation [http://www.rolfe foundation.org/]

36. Robertson Lynn M, Douglas Flora, Ludbrook Anne, Reid Garth, van Teijlingen Edwin: What works with men? A systematic review of health promoting interventions targeting men. BMC Health Serv Res 2008, 8:141.

37. Greenwald B: Promoting community awareness of the need for colorectal cancer screening: a pilot study. Cancer Nurs 2006, 29(2):|34-4|.

38. Ramirez AJ: Promoting early presentation of breast cancer. Breast Cancer Research 2008, I 0(Suppl 3).

39. Rao RS, Nair S, Nair NS, Kamath VG: Acceptability and effectiveness of a breast health awareness programme for rural women in India. Indian J Med Sci 2005, 59(9):398-402.
Publish with Bio Med Central and every scientist can read your work free of charge

"BioMed Central will be the most significant development for disseminating the results of biomedical research in our lifetime. "

Sir Paul Nurse, Cancer Research UK

Your research papers will be:

- available free of charge to the entire biomedical community

- peer reviewed and published immediately upon acceptance

- cited in PubMed and archived on PubMed Central

- yours - you keep the copyright

Submit your manuscript here:

http://www.biomedcentral.com/info/publishing_adv.asp
BioMedcentral 